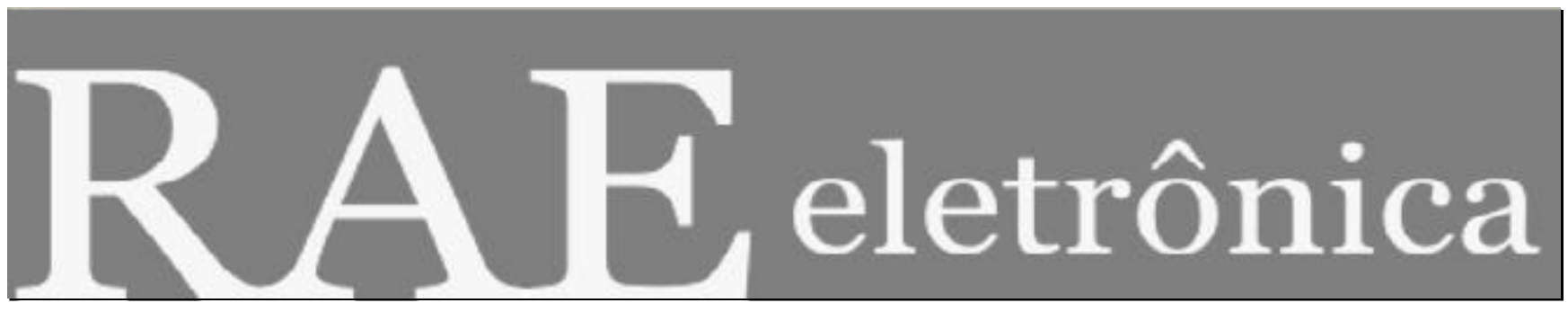

\title{
O HOMEM DO SÉCULO XXI: SUJEITO AUTÔNOMO OU INDIVÍDUO DESCARTÁVEL
}

Por:

\section{Eugène Enriquez, Université Paris VII}

RAE-eletrônica, v. 5, n. 1, Art. 10, jan./jun. 2006

http://www.rae.com.br/eletronica/index.cfm?FuseAction=Artigo \&ID=4263\&Secao=PENSATA\&Volu $\mathrm{me}=5 \&$ numero $=1 \& \mathrm{Ano}=2006$

CCopyright, 2006, Revista Réfractions. Artigo originalmente publicado sob o título 'L'homme du $\mathrm{XXI}^{\mathrm{e}}$ siècle: sujet autonome ou individu jetable”, de Eugène Enriquez, na revista Réfractions, n. 12, abr.-maio 2002, p. 125-136. Publicado com autorização do autor e da revista Réfractions. Todos os direitos, inclusive de tradução, são reservados. http://refractions.plusloin.org

A RAE-eletrônica é a revista on-line da FGV-EAESP, totalmente aberta e criada com o objetivo de agilizar a veiculação de trabalhos inéditos. Lançada em janeiro de 2002, com perfil acadêmico, é dedicada a professores, pesquisadores e estudantes. Para mais informações consulte o site www.rae.com.br/eletronica.

RAE-eletrônica

ISSN 1676-5648

(C2006 Revista Réfractions

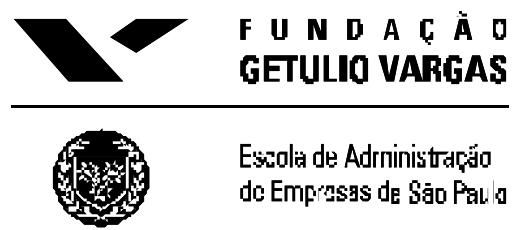




\section{O HOMEM DO SÉCULO XXI: SUJEITO AUTÔNOMO OU INDIVÍDUO DESCARTÁVEL}

Por que escolher um tema como esse: simplesmente porque o vínculo social, no momento atual, se desfaz cada vez mais rapidamente e porque vemos aumentar uma violência que não é a violência fundadora do direito, nem a violência necessária às relações humanas (Kant notou que, sem discordância, seríamos apenas carneiros balindo), mas uma violência por excesso, um mal radical elementar, como diria Levinas, que visa suprimir não somente o indivíduo, mas o sentido, fazendo com que nada na vida tenha sentido.

Já antes da Segunda Guerra Mundial, Freud e Valéry nos preveniram. Em O mal-estar da civilização (1930), Freud notou que nós, nas sociedades ocidentais, tínhamos chegado a um nível de “tensão intolerável”, tensão política e psíquica, e que a humanidade seria capaz de se destruir definitivamente, de forma que aquilo que lhe havia permitido progredir tornar-se-ia a causa de seu desmoronamento. Paul Valéry, por seu lado, em suas Reflexões sobre o mundo atual (1945) sublinhava o fato de que "as civilizações sabem que são mortais" e a tendência das sociedades européias a renunciar à sua missão.

Acrescentamos duas frases mais recentes: a primeira, de Georges Bataille: "A humanidade inteira está ameaçada a reduzir-se a um imenso sistema de escravidão para todos"; a segunda, de D. Rousset: "Os homens normais não sabem que tudo é possível".

Proponho, pois, uma visão trágica da vida, não para nos deixar invadir pela fatalidade, mas para examinar lucidamente se uma outra via é possível, se podemos fazer prevalecer a civilização, apesar das ambigüidades, sobre a barbárie. Partimos de uma constatação:

1. De um lado, a partir do século XIX, com o discurso sobre a emancipação e o progresso humano, e mais particularmente durante todo o século XX, vimos se afirmar a idéia de que o indivíduo devia e podia tornar-se um sujeito autônomo, sujeito histórico (como disse Walter Benjamin: "Todo indivíduo é um ser histórico”), sujeito de direito, sujeito psíquico e sujeito moral, portanto, sujeito de suas ações.

Pela Declaração de Direitos do Homem e do Cidadão, de 1789, e pela Declaração Universal dos Direitos do Homem, da ONU, de 1948, o homem é reconhecido, na sua eminente dignidade, como tendo direito a ter direitos.

Vou traçar rapidamente essa emersão do sujeito. ${ }^{1}$ O sujeito histórico, ou seja, aquele que intervém no nível político, que contribui para definir a orientação da sociedade e que participa 
diretamente das decisões essenciais relativas à vida e à morte, apareceu na aurora do século V a.C., em Atenas.

O cidadão (é certo que algumas pessoas não eram consideradas como tal: os escravos, os imigrantes, as mulheres, as crianças) utilizava sua liberdade para tomar parte ativa, se desejasse, do funcionamento da comunidade. Todos os cidadãos têm o mesmo direito à palavra e devem ser ouvidos no espaço público do debate, ainda que sejam os sofistas que cativem a atenção por mais tempo. Se, após o desaparecimento da democracia ateniense, esse tipo de sujeito apagourse (a tal ponto que La Boétie pôde se perguntar se não existiria um desejo de submissão, uma servidão voluntária, permitindo ao "Um" governar, sem freios, todos os demais) durante os períodos feudais e monárquicos, ele reaparece na Inglaterra quando do estabelecimento da Bill of Rights (Carta de Direitos) e das revoluções Americana e Francesa. É certo que nem todas as pessoas receberam, imediatamente e sem resistências, os atributos da soberania (as mulheres, na França, tiveram direito ao voto apenas em 1945), mas progressivamente os diversos segmentos de uma nação puderam intervir no debate público e influenciar o caminho da nação na direção que eles consideravam a melhor.

Para que o indivíduo pudesse tornar-se um ser histórico, foi preciso naturalmente que ele se tornasse um ser de direito, ou seja, alguém que desfrute de direitos (direitos políticos, direitos civis e, mais recentemente, direitos sociais) e sobretudo que seja reconhecido como tendo o direito, como ser humano e como cidadão de um país, de gozar da totalidade dos direitos acordados (ou arrancados) ao conjunto dos cidadãos nacionais ou ao conjunto dos homens residentes num território. O sujeito de direito é, pois, um indivíduo considerado, respeitado frente a todos os outros e que está sob a proteção de uma lei semelhante para todos.

É o direito que funda a liberdade real dos homens, como pensava Rousseau. Sem o direito, cada um estaria à mercê do arbítrio do tirano, do Estado, da casta ou da classe. Mas não se trata apenas de usufruir o direito. Ser um sujeito de direito significa, igualmente, assumir-se como um ator no estabelecimento das leis (seja diretamente, seja por intermédio de representantes) e agir ativamente para fundar e refundar a lei e para fornecer ao âmbito legal, assim formado, as suas fontes de legitimação. O sujeito de direito é constituído lentamente no debate contínuo contra as formas de dominação e, na maior parte do tempo, se consolida por meio de ações coletivas exemplares, que mostram sua força. Assim, não se pode esquecer que no fundamento do direito reside sempre a força, mas uma força que tende a se negar, visto que está na origem das obrigações sociais e da armadura jurídica nas quais se funda.

O nascimento do sujeito psíquico é mais recente. É à psicanálise que o homem moderno deve não apenas a descoberta crucial do inconsciente e, portanto, de sua divisão estrutural, mas sobretudo do 
reconhecimento em si de uma atividade psíquica intensa e contínua (que não se reduz às faculdades cognitivas), outorgando um grande lugar ao jogo das pulsões, dos sentimentos, dos desejos, das fantasias e dos processos de recalque, de idealização, de projeção, etc., que animam tanto a vida dos indivíduos como a do socius. Ser reconhecido como sujeito psíquico é ser respeitado em seu fórum interior, no seu trabalho de pensamento, na sua atividade de sublimação, ser protegido das "mortes psíquicas", realizadas pelos adversários que são, às vezes, os pais, e aparecer como "o mais insubstituível dos seres", dando às imagens de intimidade todo o seu vigor. Reconhecer-se como sujeito psíquico é, por outro lado, aprender a se defender da fantasia da dominação total (o famoso "mestre e dono da natureza") e se perceber como um indivíduo clivado, submetido à perda, à falta, ao trabalho de luto e ao sofrimento, dívidas a pagar para poder realizar, pelo menos em parte, o programa do princípio do prazer. O sujeito psíquico é, assim, um ser que reconhece as suas contradições e os seus conflitos, sabendo que não é totalmente senhor de sua própria casa pelo fato de existir o inconsciente, submetido à vacilação e ao medo do despedaçamento, mas capaz de fazer de suas falhas o trampolim para chegar à posição de sujeito humano e de sujeito social, estando ambos intimamente ligados, providos de uma membrana protetora (de um "eutpele", conforme D. Anzieu) e capazes de abrir-se ao mundo. ${ }^{2}$ Pode-se, pois, concluir que o homem está no caminho de sua autonomia, de ditar a si mesmo as próprias regras e de ter uma visão otimista do futuro. O homem não teria mais necessidade de grandes transcendentes para conduzir a sua própria vida.

2. Mas, por outro lado, ao mesmo tempo, vê-se surgir três problemas fundamentais: a) o reino do dinheiro, tornado um fetiche sagrado; b) o aumento do poder do Estado; c) um "retorno" identitário* ao grupo a que se pertence, e crença nos seus fundamentos.

Vou tentar ser mais preciso sobre esses três pontos e ver em que medida essa evolução favorece a evolução da autonomia do sujeito ou, ao contrário, a sua submissão ainda mais forte. A partir disso, tentarei verificar a possibilidade de algumas portas de saída.

\section{A. O REINO DO DINHEIRO}

Está ligado à submissão cada vez mais clara de todas as nações à lei do mercado mundial, produzida pela vitória da racionalidade instrumental.

Com efeito, o que triunfou a partir do século XIX e, de maneira mais evidente ainda, ao longo do século XX, não foi a racionalidade do homem tal qual fora vislumbrada no século das Luzes e pela Revolução Francesa, racionalidade dos fins últimos e dos valores irrigados pelos sentimentos e pelas paixões, tal como nos ensinaram Rousseau e Goethe, mas somente a racionalidade instrumental, aquela 
que se interessa apenas pelos meios a serem utilizados e que responde só à questão: como? Jamais à questão: por quê? Essa predominância se traduz pelo surgimento apenas da racionalidade econômica, aquela que permite o cálculo dos melhores meios e dos melhores métodos, cálculo de custos e de vantagens, e que submete todo mundo ao reino do dinheiro.

Essa racionalidade deformada, limitada, sinaliza o advento de uma forma de pensamento e de um estilo de ação perverso, já antecipado no século XVIII pelo marquês de Sade, ao dizer que, se o homem fosse totalmente livre, seria livre para se vender, conduzido à "venalidade generalizada". E que, se todos os homens fossem iguais, alguns poderiam usar o seu poder e a sua riqueza que são desigualmente distribuídas para intimidar outros, para rebaixá-los ao nível de objetos, para usá-los como instrumentos de seu próprio gozo.

De certa maneira, podemos afirmar, sem risco de sermos contraditados, que o mundo atual se tornou sádico. Os antigos valores de mérito, trabalho, honra, prestígio e "a herança histórica, usada pelo capitalismo, inclusive a honestidade, a integridade, a responsabilidade, o cuidado no trabalho, o respeito aos outros" (Castoriadis, 1996), foram desvalorizados em prol de um único valor: o dinheiro. “Tudo se compra e tudo se vende." O axioma de L. Walras é o de nossa sociedade, de onde deriva a possibilidade de corrupção generalizada, tanto dos grandes como dos pequenos, comportamento perverso por excelência. Um novo impulso foi dado a essa tendência pela predominância contemporânea das estratégias financeiras. O dinheiro deve criar dinheiro, de acordo com a necessidade, sem passar pela mercadoria, e assim criar novas riquezas, passando por cima das estratégias industriais que visam o desenvolvimento. Assiste-se a um aumento contínuo das desigualdades internas e externas, a um papel preponderante dos acionistas e dos titulares de fundos de pensão em relação àquele dos administradores e trabalhadores; à globalização das trocas que beneficiam essencialmente aos paises ricos - que sabem como se proteger quando lhes parece necessário; aos avanços tecnológicos dos países já desenvolvidos (as outras nações se encontram em situação de dependência crescente, apesar das resistências), que se tornam instrumentos das grandes potências. A guerra econômica se intensifica a cada dia.

Conseqüências ao nível coletivo: dissolução do vínculo social, exclusão ou "desvinculação social" (R. Castel, 1995), competição exacerbada, pilhagem do planeta, enfraquecimento dos movimentos sociais, diminuição das lutas sindicais, e, por outro lado, importância crescente das empresas, que querem ser "as instituições divinas", e de suas conseqüências ao nível individual: os indivíduos devem se integrar, ou melhor, se identificar às organizações das quais fazem parte, idealizálas, colocando os valores organizacionais - seu próprio ideal do ego - no lugar dos seus próprios valores, transformar-se em instrumentos submissos, dóceis mesmo, e sobretudo acreditar, se lhe 
disserem e se eles se sentirem responsáveis enquanto sujeitos, que estão a caminho da autonomia. É a psicologização dos problemas que se coloca em prática. Uma instituição e uma organização não são menos organizadas ou geridas dentro dessa concepção. Se elas fracassam, é sempre ao indivíduo que a responsabilidade é imputada. Assim, os indivíduos estão sempre em situação de prova, em estado de estresse, sentem queimaduras internas, tomam excitantes ou tranqüilizantes para dar conta da situação, para ter bom desempenho, para mostrar sua "excelência" (entramos numa civilização de dopping); e, quando esses indivíduos não são mais úteis, eles são descartados apesar de todos os esforços despendidos. O homem tem, cada vez mais, a solidão como companheira. Ele pode se transformar em alguém "inútil ao mundo", para retomar uma velha expressão da Idade Média, um excluído definitivo, sem esperança de um dia voltar a ser "incluído". No século XIX, as pessoas que formavam o "exército de reserva do capital" eram excluídas temporariamente do processo produtivo, mas sabiam que um dia poderiam voltar a fazer parte do grupo de incluídos, o que não é o caso atualmente. Para dizer algo sobre o futuro, que parece bem sombrio a esse respeito, as novas tecnologias favorecem a eliminação de milhares de pessoas no mercado de trabalho.

A racionalidade instrumental e as estratégias financeiras atingem, pois, o objetivo: utilizar o sujeito, que acredita ser em grande parte autônomo, para superexplorá-lo e aliená-lo. O processo de alienação é tão mais insidioso que muitas pessoas colaboram com a própria alienação. Tornam-se utensílios manuseados pelos dominantes no alto de sua potência. Estes últimos tornam-se cada vez ou mais perversos ou mais paranóicos porque têm o gosto pelo poder desmedido. A perversão pode, aliás, assumir duas formas: a) uma forma ativa, na qual o perverso utiliza, com gula, os demais para torná-los dependentes e submissos, e contribuir à sua própria servidão e humilhação; b) uma forma passiva, a apatia, tal como já observada no século XVIII por Sade. O apático é um indivíduo que não sente nenhuma emoção. É insensível, e vê os demais apenas como "coisas" abstratas, que podem, portanto, ser eliminadas física ou psiquicamente, se necessário, sem que ele se sinta nem alegre nem incomodado (esse tipo de pessoa se desenvolve em nossas sociedades, que dizem que os chefes não devem ter "états d'âme", $e^{* *}$ e devem apenas fazer o seu trabalho da maneira mais perfeita). Esses indivíduos (paranóico, perverso ativo, perverso apático) são naturalmente hostis às pessoas desviantes, não-conformes, aos sujeitos que pensam que são "causa de si”, como indicou M. Enriquez (1984). O mundo atual tende a tornar-se o do crescimento do desprezo, da generalização da desconsideração, do desrespeito, da recusa da diferença a que tem direito todo ser humano. 


\section{B. AUMENTO DO PODER DO ESTADO}

Se o indivíduo é submetido às estratégias financeiras, ele o é igualmente ao Estado do qual é cidadão. A esse respeito é preciso apontar, com H. Arendt (1973), para uma contradição entre os direitos do homem, que visam o universal no homem, e os direitos do cidadão, que insistem na especificidade desse homem e seu sentimento de pertencer a uma nação, o que faz surgir e desenvolver o apátrida, o refugiado. É certo que ele tem direitos no seu país, mas direitos que dependem apenas da boa vontade do Estado, mesmo daquele que é democrático. Deve respeitar e submeter-se a todas as leis, mesmo àquelas que lhe parecem injustas ou arbitrárias, e mesmo se for tratado como cidadão de segunda classe, como o são os trabalhadores informais da América Latina.

Ele é também submetido à vontade de seu Estado de fazer guerra às demais nações (que foi no século $\mathrm{XX}$, na maior parte do tempo, uma guerra ideológica, total e de massa) ou à suas próprias determinações (guerra civil, genocídios do tipo que se viu no Camboja, em Ruanda, por exemplo). O homem não deve ser apenas um trabalhador que contribui para a riqueza de sua nação, ele deve ser e querer ser um guerreiro. Não é sem motivo que E. Jünger, em seu livro Le travailleur et la mobilisation totale (1930), unificou as figuras do trabalhador e do guerreiro: todo trabalhador permite à sua nação ganhar, portanto ele é um guerreiro; todo guerreiro realiza um trabalho necessário à nação - preservá- la de outras ou de levantes internos -; ele é, portanto, um trabalhador. De qualquer forma, o Estado pode exigir dele uma identificação completa aos seus valores - como no caso da Alemanha nazista e do sistema totalitário soviético - e definir quem tem o direito e o dever de fazer parte do Estado- nação e quem deve ser descartado, rejeitado ou eliminado. Algumas pessoas tornam-se indivíduos cuja "vida é indigna de ser vivida". Aquele que não é incluso no discurso do amor comum não é digno de viver, daí os campos de concentração e os campos de morte.

Michel Foucault escreveu estas linhas que nos convidam a meditar: "O homem, durante milhares de anos, era aquilo que dele pensava Aristóteles, um animal vivo e cada vez mais capaz de uma existência política. O homem moderno é um animal vivo cuja vida é constantemente questionada, não importa o que ele faça". ${ }^{3}$ Ele mostra, assim, que nascia a biopolítica, ou seja, que a vida tal como ela era, tornara-se uma questão política. O que leva G. Agamben, autor de Homo sacer (1997) a dizer: "A politização da vida constitui o acontecimento decisivo da modernidade".

Assim, o homem dito autônomo, o homem sacralizado e sagrado dos tempos modernos, pode vir a ser como o Homo sacer do antigo direito romano, um indivíduo não sacrificável - pois isso significaria que ele ainda é parte da espécie humana -, mas sim um indivíduo passível de ser morto sem sanção. O Estado total (ou totalitário), que coloca em prática essa biopolítica, funciona sob o modo da 
exceção que se torna a regra (o que leva C. Schmitt, teórico do Estado total, a dizer: "a fonte da lei é a palavra do Führer" - quanto aos stalinistas e aos maoístas, sabemos que ambos tinham sempre razão). O homem pode ser assim rebaixado à condição de sub-homem.

Vê-se, então, que o homem levado em consideração enquanto homem (e não enquanto o que ele era antes: camponês, artesão, comerciante, etc.) pode ser totalmente sujeitado. Retire-se dele a cidadania, e ele não é mais um homem; rebaixe-o à condição de animal, e ele não é mais um homem. E tornado igual a todos, ele pode tornar-se um idêntico, um clone, e pode ser substituído por um outro idêntico (a racionalidade instrumental, que considera cada um apenas um objeto, reforça essa tendência). Quanto aos dominantes, cresce a tentação de serem paranóicos, perversos ativos e perversos apáticos (carrascos que se habituam a tudo). É certo que não estamos mais nos tempos do Estado total ou totalitário. A democracia representativa triunfou. Mas, de fato, como vimos, é a regra do dinheiro que adveio. O que torna o sujeito menos dominado pelo Estado (exceto nas ditaduras) é substituído pela sua sujeição ao dinheiro. Os indivíduos tornam-se meros consumidores ou "mercenários". O cinismo se desenvolve. Os políticos parecem cada vez menos críveis, pois um bom número deles se deixa corromper. ${ }^{4}$ Um novo "mal-estar" está em vias de aparecer.

\section{OS RETORNOS IDENTITÁRIOS}

Contra todas as formas de violência (do dinheiro, do Estado), contra esses "monstros frios" (na expressão de Nietzsche), o que é possível instaurar para se recriar um mundo caloroso, agradável, e viver, no qual cada um possa ser reconhecido? Dois tipos de reações podem ser aventados.

\section{Uma reação no nível coletivo}

Muitas pessoas tentam reencontrar suas raízes. O tema "enraizamento", caro a Simone Weil, retoma o seu vigor. Ele se traduz por um interesse, e às vezes por uma idealização, do regional, do local, do grupo a que se pertence. Retorno a terra, às músicas e à linguagem local. Na França, percebe-se a importância dada pelos bretões e pelos corsos à utilização da língua deles, à promoção de seu reduto e à sua música popular; retorno a alguns costumes, modos e danças de antigamente. Trata-se de reencontrar um convívio, o prazer de estar junto, de conversar longamente, de afirmar sua diferença cultural, assim como os afro-americanos e os afro-brasileiros podem reconquistar uma dignidade que perderam. Trata-se de uma reação normal e sã que tem por objetivo restaurar um mundo passível de ser vivido entre irmãos e irmãs. Entretanto, essa reação envolve perigo, pois engendra perigos essenciais, tais como o retorno aos nacionalismos mais virulentos, por exemplo, o nacionalismo albanês ou sérvio, 
O HOMEM DO SÉCULO XXI: SUJEITO AUTÔNOMO OU INDIVÍIDUO DESCARTÁVEL

Eugène Enriquez

para não falar dos nacionalismos da África negra, que se traduzem pela eliminação e pelo massacre (Ruanda) de populações inteiras; a renovação dos integrismos religiosos, a proliferação de seitas, de comunidades fechadas (dos guetos), gangues de bairro etc.; enfim, um "espírito de corpo" pervertido.

Se é importante respeitar as diversas culturas, como Lévy-Strauss sublinhou em Race et histoire, no qual demonstrou que nenhuma cultura pode se orgulhar de superioridade em todos os domínios sobre outra, é essencial também que os povos não se refugiem em comunidades que se querem estáticas. O comunitarismo afasta os homens uns dos outros, e pode fazer renascer aquilo que Freud (1930) chamou de o "narcisismo das pequenas diferenças” e que G. Devereux (1972) julga em termos severos: 'Se a gente é apenas um capitalista ou um proletário, um ateniense ou um espartano, a gente está bem perto de não ser grande coisa ou mesmo coisa alguma”.

\section{Uma reação no nível individual}

Vêem-se cada vez mais pessoas que se voltam à sua própria identidade, que cuidam apenas de "si", de sua vida privada, de seus investimentos cotidianos, de sua família. O homem, então, não se sente mais fazendo parte de uma espécie humana e não participa mais do trabalho da civilização. Considera os outros apenas obstáculos ou objetos de prazer.

Ademais, à força de ser só e responsável, o homem acabou por considerar seu eu "como um fardo", conforme observado por R. Sennett (1974). Ele está cansado de si mesmo (A. Ehrenberg, 1998) e se torna desamparado e deprimido, motivos para recorrer às drogas para manter-se de pé e ter o sentimento de ser criativo. $\mathrm{O}$ estresse permanente que assalta os atores sociais lhes impede de serem criativos (desenvolvimento do conformismo), e eles acabam por mergulhar na mediocridade, na “insignificância” (Castoriadis, 1996), sinais incontestes da barbárie e de uma incapacidade para a transgressão.

Se se reconhecer como sujeito é essencial, ver-se apenas como um individuo indiferente aos outros e ocupado apenas com suas próprias preocupações é simplesmente mortífero.

Existe uma saída? Pode-se reconstituir o vínculo social?

Scott Fitzgerald dizia: “É preciso saber que o mundo é sem esperança e, contudo, decidir mudálo". Eu gostaria de retomar igualmente um verso do poeta alemão Hölderlin, do qual gosto muito: "Lá onde crescem os perigos, cresce também a salvação".

Atualmente as pessoas são cada vez mais capazes de fazer o diagnóstico que acabo de apresentar. Podemos assinalar os sinais positivos: a família se reconstrói, mesmo que o faça com mudanças. Não se proclama mais a morte da família, como em 1968. Ela é, apesar de tudo, um lugar de 
calor e de intimidade. Surgem numerosas associações (os "restos du cœur", "** as ações contra o desemprego, direito à habitação, as redes SOS de amizade, etc.).

Os grandes discursos ideológicos desapareceram. Fracassaram porque se tornaram mortíferos. Mas esse desaparecimento não impediu, apesar de tudo, a aparição, há alguns anos, de movimentos sociais engajados, nos quais os objetivos não são sempre precisos, mas que questionam a sociedade atual. É certo que não é possível dizer precisamente quais serão as conseqüências de suas ações. Isso não impede que esses movimentos existam e que já se façam ouvir. Progressivamente, as pessoas se põem a dizer que não querem mais um Estado totalitário e que tampouco querem um Estado liberal que não se preocupe mais com a proteção social. Querem um Estado de outro tipo, que exponha os problemas em sua nudez, tentando resolver as questões urgentes, consultando as populações e levando em conta suas opiniões, e não seja um Estado estritamente gestor. Existe, pois, uma demanda pela formulação de novos ideais que não são grandiosos, mas que também não são puramente ideais de gestão. Ademais, como se sabe que não se pode pedir tudo ao Estado, vêem-se ações assumidas cada vez mais por grupos e associações (anti-racistas, auxílio aos clandestinos, de socorro aos carentes, etc.).

Estamos assistindo a uma lenta mas real renovação da sociedade civil. Esse é um ponto extremamente importante. Não se pode pedir tudo ao Estado, então é preciso pôr as mãos na massa, tanto individual quanto coletivamente. $\mathrm{O}$ indivíduo não deve se perder no coletivo, deve manifestar plenamente sua individualidade e ao mesmo tempo trabalhar com os outros para construir alguma coisa. Nada pode ser feito sem envolvimento individual forte nas ações políticas, que são pensadas, discutidas. E as pessoas começam a crer. ${ }^{5}$

Um outro ponto que me parece muito importante é a renovação da noção de ética. Falou-se muito de ética nos negócios. Não creio nela, e ela é perigosa, pois se trata mais de uma deontologia do que de ética, mais uma prescrição do que propriamente princípios reguladores. Mas a preocupação ética torna-se importante em todos os lugares, não somente nos comitês de bioética ou na vida das empresas, mas na vida de cada um de nós. Atualmente nos recolocamos algumas questões fundamentais que eram ocultadas.

Eu gostaria de citar algumas delas, em particular as questões enunciadas por Max Weber: o que é a ética da convicção ou a ética da responsabilidade? Até que ponto podemos ter convicções sólidas e discutir fortemente a partir do que pensamos, e ao mesmo tempo nos sentir responsáveis pelas consequiências de nossas ações? Podemos também nos interrogar sobre o fato de que, mesmo que tenhamos convicções estabelecidas, elas não são necessariamente justas, e que, pois, é preciso colocálas à prova da comunicação e da discussão. É por isso que parece muito importante que se desenvolva o que Habermas chamou de ética da discussão (1983). O importante é que as pessoas tenham o máximo 
possível de informações, e que possam discutir no espaço público para permitir que os problemas sejam verdadeiramente tratados. Estamos longe disso. A informação que temos não é nem total nem pertinente. Porém, a demanda por informação aumenta.

O indivíduo começa a perceber que não é apenas à base de estimulantes que ele pode encontrar saídas, que não é somente adotando todas as próteses possíveis que ele pode se adaptar, mas que é principalmente se interrogando sobre as suas capacidades, seus limites, sua mortalidade, individualmente e com os demais. $\mathrm{O}$ indivíduo então se confessa capaz de um trabalho de luto, de um trabalho de interrogação, que pode levá-lo a analisar-se, a trabalhar o seu "fórum interior", não para fazer análise pela análise, mas para tentar saber por que faz tal coisa e que sentido lhe atribui. É dizer que retorna de maneira fundamental a algo que estava em vias de desaparecer: a questão do sentido. Os seres humanos são seres em busca de sentido. É a definição fundamental de ser humano e ser social. De outro modo, seríamos apenas animais totalmente programados.

Os sujeitos se dão cada vez mais conta da identidade dos problemas com os quais se defrontam. São capazes de começar a se interrogar. É necessário que haja pessoas que possam ajudá-los a analisar o que estão fazendo, a fim de que possam pensar novos projetos, construir novas instituições, transgredir as regras que não valem nada e guardar aquelas que valem algo, retomar o que haviam esquecido, fazer experimentação social e, talvez, um dia formar um novo paradigma social e humano. Esse paradigma implicaria ter-se maior consideração pelos outros. Atualmente nos perguntamos: "Em que consiste a dignidade do ser humano? O que é o respeitar o ser humano?"

Existe um esforço nesse sentido. A renovação da ética, a emergência de um desejo de reencontrar a alegria em trabalhar e em viver junto, o desejo de amizade, de convívio pode reconstruir o tecido social (Freud viu isso): é o amor mútuo (a libido associativa), que está no fundamento do vínculo social, e não somente a morte mútua. É graças a ele que se pode vislumbrar o “enfraquecimento do Estado".

Existem em nossas sociedades muitas mortes, mortes físicas, mortes psíquicas, mas é o amor seja como amor total, seja como ternura, amizade, camaradagem, solidariedade, fraternidade - que deve nos animar. É preciso pensar não apenas na liberdade e na igualdade. A fraternidade é também alguma coisa de essencial. É a percepção real de que as sociedades não podem se fundar nem perdurar se não desenvolvem um mínimo de prazer, até o regozijo de estar junto. Eu diria que é preciso reinstaurar o que Freud dizia: é preciso, mesmo assim (e é muito difícil), poder seguir o programa do princípio do prazer. E, naturalmente, a realidade é sempre contra. Mas o programa do princípio do prazer é, levando em conta a realidade, tentar se reconhecer mutuamente, fazer as coisas junto, e me parece que as pessoas mais mortíferas, sempre mais numerosas, já começam a desencantar um pouco. 
O vínculo social não se construirá a não ser que queiramos construí-lo, e se esse desejo for compartilhado por um grande numero de pessoas. $\mathrm{O}$ voluntarismo, naturalmente, não é suficiente, mas sem ele nada é possível. A revolução não pode ser feita em um dia, mas se faz todos os dias nas relações cotidianas que mantemos, como já pensava W. Reich. E aí está a entrada para um convívio verdadeiro, a edificação de uma democracia que mereça esse nome, na qual o amor e a alegria estejam e continuem a estar presentes. Resta, pois, trabalhar nesse projeto, tentando afastar as tendências mortíferas (sempre reconhecendo-as, pois a pulsão de morte é sempre operante), e fazer triunfar, tanto quanto possível, o prazer e o amor mútuo. Isso pode parecer utópico, mas como eu já disse tempos atrás: “As sociedades que não sonham são sociedades que morrem”. Certamente a divisão originária não cessará, e é importante que permaneça para lançar os movimentos sociais, instituir os desejos. Caso contrário, há o risco de recriar as sociedades "holistas", fusionais, sem conflitos e sem contradições. De qualquer forma, é preciso lembrar do conselho de Maquiavel: 'E muitas se imaginaram repúblicas e monarquias que nunca foram vistas nem conhecidas como verdadeiras. Com efeito, o que vivemos se distancia tanto do que deveríamos viver que aquele que abandona o que está fazendo para dedicar-se ao que deveria fazer acaba mais por se destruir do que se preservar".

Os profetas se enganaram: não há o fim da historia, não há sociedades felizes nem futuro radioso. Aqueles que acreditaram nisso destruíram os homens e as sociedades em que viveram. E, no entanto, nem por isso é preciso renunciar à visão de sociedades mais justas, menos alienantes, nas quais os homens seriam mais inclinados à sublimação que à idealização ou ao recolhimento em si mesmos. Se, como pensava Castoriadis (1997), "falar já é sublimar", estamos prontos para dar vida ao aforismo de Nietzsche: "É uma bela loucura, falar - com isso, o homem dança sobre e acima de todas as coisas", e poderemos, ao aceitar a divisão originária no social e no individual (o inconsciente e o consciente permanecem clivados), encontrar aquilo que Nietzsche chamou de caos; ou seja, favorecer a criação de uma sociedade que "dança" e não a de uma sociedade que "pesa". 6

\section{NOTAS}

${ }^{1}$ Retomo aqui uma passagem de meu texto Émergence du sujet et formes d'autorité, publicado na revista Pour, n. 165, GREP, 2000.

${ }^{2}$ Fim da reprodução do artigo citado.

${ }^{3}$ Citado por G. Agamben.

${ }^{4}$ Não se pode esquecer que, se a "virtude" está no fundamento da democracia, ela é sempre corruptível. Tanto Maquiavel quanto Montesquieu insistiram nesse ponto. 
O HOMEM DO SÉCULO XXI: SUJEITO AUTÔNOMO OU INDIVÍDUO DESCARTÁVEL

Eugène Enriquez

${ }^{5}$ Giordano Bruno já afirmava: 'Descobrirás em ti mesmo o meio de progredir à medida que descubras uma identidade distinta a partir da pluralidade [...] A partir de múltiplos elementos, adaptar a si mesmo tudo aquilo que tenha forma e unidade". Citado por U. Eco (1965).

${ }^{6}$ Nietzsche escreveu: "É preciso ter o caos em si para dar à luz uma estrela que dança", e ele opunha a música de Carmen, de Bizet, à de Wagner, qualificando a primeira de música que "dança" e a segunda, de música que "pesa".

\section{Notas da tradutora}

* No original "repli identitaire", que pode significar um recurso de isolamento do grupo de referência ou um fechamento do indivíduo em si mesmo. Estamos traduzindo como ato de retorno a si e/ou ao grupo, em detrimento do mundo exterior e do social.

** Literalmente, "estados de alma". Usamos o termo para significar alguém que não sente e/ou expressa emoções, empatia, estresse ou sensibilidade ao outro; ou ainda, que é completamente indiferente ao que possa acontecer ao outro afetado por sua ação ou decisão.

*** Refere-se literalmente à cadeia de Restaurantes do Coração, formada, sustentada e gerida por voluntários, que atendem a populações carentes em toda a França.

\section{REFERÊNCIAS BIBLIOGRÁFICAS}

AGAMBEN, G. Homo sacer. Paris: Seuil, 1997.

ARENDT, H. L’imperialisme. Paris: Seuil, 1984.

CASTEL, R. Les métamorphoses de la question sociale. Paris: Fayard, 1995.

CASTORIADIS, C. La montée de l'insignificance. Paris: Seuil, 1996.

DEVEREUX, G. Ethnopsychanalyse complémentariste. Paris: Flamarion, 1972.

ECO, U. l'Euvre ouverte. Seuil. Paris: 1965.

ENRENBERG, A. La fatigue de soi. Paris Odile Jacob, 1998.

ENRIQUEZ, M. Au carrefour de la haine. Paris L'EPI, 1984. 
FREUD, S. Malaise dans la civilisation. Paris: PUF, 1971.

HABERMAS, J. La théorie de l'agir communicationnel. Paris: Fayard, 1983.

JÜNGER, E. La mobilisation totale. Paris: Gallimard, 1990.

LÉVINAS, E. Quelques réflexions sur la philosophie de l’hitlérisme. Paris: Rivages Poche, 1997.

LÉVY-STRAUSS, C. Race et histoire, Paris: Folio, 1952.

SENNETT, R. Les tyrannies de l'intimité. Paris: Seuil, 1979.

VALÉRY, P. Regards sur le monde actuel et autres essais. Paris: Gallimard, 1945.

WEBER, M. Le savant et le politique. Paris: Plon, 1959.

\section{Artigo convidado. Aprovado em 12.02.2006.}

Artigo originalmente publicado com o título "L'homme du XXI" siècle: sujet autonome ou individu jetable", de Eugène Enriquez, na revista Réfractions, n. 12, abr.-maio 2002, p. 125-136. Publicado com autorização do autor. Também disponível em <http://refractions.plusloin.org/article.php3?id_article=85>

\section{Tradução para o português de Maria Ester de Freitas.}

\section{Eugène Enriquez}

Professor Emérito da Université Paris VII e do Laboratoire de Changement Social. Doutorado em Psicossociologia e Sociologia Clínica. Membro fundador da ARIP - Association pour la Recherche et l'Intervention Psychosociologiques. Redator-chefe da revista Connexions e co-redator da Revue Internationale de Psychosociologie.

Interesses de pesquisa nas áreas de psicossociologia das organizações e filosofia política e moral. Contato (telefone): 33142490555

Endereço: 56, quai de jemmapès, bat. A - 75010, Paris - France. 